Article

\title{
Overcoming the Barriers to the Diffusion of Sustainability Reporting in Italian LGOs: Better Stick or Carrot?
}

\author{
Davide Giacomini $^{1, *}$ (1) , Laura Rocca ${ }^{2}$, Cristian Carini ${ }^{2}$ (D) and Mario Mazzoleni ${ }^{1}$ \\ 1 Department of Economics and Management, University of Brescia, Contrada Santa Chiara, 50, \\ 25122 Brescia, Italy; mario.mazzoleni@unibs.it \\ 2 Department of Law, University of Brescia, Contrada Santa Chiara, 50, 25122 Brescia, Italy; \\ laura.rocca@unibs.it (L.R.); cristian.carini@unibs.it (C.C.) \\ * Correspondence: davide.giacomini@unibs.it; Tel.: +39-030-2988570
}

Received: 22 November 2017; Accepted: 4 January 2018; Published: 9 January 2018

\begin{abstract}
The role of public-sector organizations (PSOs) in promoting the agenda of sustainability accounting and accountability is not often adequately considered. In the public sector realm, local governments are close to their communities and thus have a particularly important role to play in the pursuit of sustainability goals. Hence, further research is needed to understand if Local Government Organizations (LGOs) are using reporting tools to promote sustainable development. The empirical data showed that the Sustainability Report (SR) is not being as widely used as in past years. Over time, the majority of Italian municipalities have not initiated or continued sustainability reporting due to some barriers including cost reduction, voluntariness, and low SR effectiveness. The findings suggest the popularity of SRs in Italy is falling and the SR tool appears to be "mere trend reporting based on descriptive indicators leading to decreasing interest from internal and external audiences". The carrot has been unsuccessful. Perhaps the implementation of mandatory requirements could alternatively be used as a stick.
\end{abstract}

Keywords: sustainability reporting; local government organizations; sustainable development; mail survey; public sector

\section{Introduction}

Sustainable development (SD) is a key research and policy issue [1]. The concept of sustainable development was institutionalized at the United Nations Conference on Environment and Development (UNCED) held in Rio de Janeiro in June 1992. During this conference, about 170 governments agreed on a common commitment, called Agenda 21, which included programs and aims in the field of social and environmental sustainability. Agenda 21 assigned a specific role to Local Governments Organizations (LGOs) because many of the issues addressed by Agenda 21 have their roots in local activities. Hence, public institutions are especially involved not only at the central government level but also at the local level.

The role of LGOs in attaining sustainability is essential. The United Nations Conference on Sustainable Development, called Rio +20 , emphasizes the issues related to sustainability and the function of the Public Sector Organization (PSOs) in addressing these topics: "Given the scale of the challenges, the international community will not make meaningful progress without much greater action by governments in the coming years and decades" [2]. Essentially, LGOs are the institution closest to the citizens and to economic and social organizations; they have the task of promoting a culture of sustainable development [3,4]. 
The debate about SD includes both the identification of the actors required to implement programs, and the methods and tools to achieve the goals. From this perspective, accounting research related to reporting is considered useful for the promotion of the SD agenda [5-7]. Several types of reports address sustainability issues, and may contain social aspects only or environmental items only, or these aspects may be combined with others such as economy, safety, corporate governance, ad risks. In this paper, the reports will be identified using the term "sustainability reports" (SR). The sustainability reports are the external tools in the form of written reports that communicate the public policies of LGOs about sustainability matters [8,9].

This study focused on the sustainability reports of the local governments. The purpose of this study was to analyze the trends and barriers to the use of SRs by Italian LGOs.

To examine the extent to which Italian LGOs are reporting on sustainability, we used an email survey. As the literature has suggested $[10,11]$, the majority of Italian municipalities do not produce a sustainability report. Two specific research questions (RQ) were considered:

RQ 1: Are Italian LGOs reporting on sustainability nowadays?

RQ 2: Which are the barriers to the diffusion of the SR?

The paper contributes to the sustainability reporting in the field of LGOs research. This study provides insight into the status of sustainability reporting in LGOs using quantitative research that shows the trends in reporting practices over a long time period. From a theoretical perspective, this study contributes to the existing literature on public sector sustainability reporting by analyzing the barriers to SR adoption. Considering that over $90 \%$ of Italian municipalities do not produce a SR, Italy is a relevant case study because a long evaluation period would allow a deeper understanding of the reasons for not adopting the SR that validate the trend. Based on the findings, we suggest policy implications for local actors to overcome the barriers and enhance the adoption of SR.

The paper is structured as follows. The next section provides a literature review and a theoretical framework for the adoption of SR; the third section describes the institutional context of Italian LGOs. The fourth section presents the methodology. The fifth paragraph introduces and discusses the results. Finally, the last paragraph presents conclusions, policy implications, and future research recommendations.

\section{Literature Review and Theoretical Framework}

Terms like "sustainable development" and "sustainability" do not have a universal definition [12-14]; the most common definition comes from the Brundtland Report of the United Nations World Commission on Environment and Development (WCED, 1987). SD is defined as "development that meets the needs of the present without compromising the ability of future generations to meet their own needs".

Starting with the Bruntdland Report definition, the concept of sustainable development had to be translated from theory into practice: according to Williams et al. [15], a need existed "to move the term from a theoretical concept to an operational concept". This means transferring sustainable strategies into sustainable practical decisions and activities.

This process is harder to put into practice, but "the local government has a key role to play if the sustainable development agenda is to be pursued" [2,3,15]. According to previous studies, the definition of sustainable development at the local community level that we decided to use is the local activities that create the conditions for economic growth without damage to the local territories while increasing social equity.

The attention to sustainability matters by local governments is one of the core themes of Agenda 21 [16]. The transparency of social, environmental, and governance information in LGOs is also an issue at the European level [17]. To study the empirical application of sustainable development, one of the public accountability tools, from an external point of view, is the sustainability report $[8,9]$. 
The majority of research in sustainability reporting has focused on the private sector and it has been receiving increasing amounts of attention [18-24]. Only in recent years has an increased interest on this topic gained traction in the public sector [25-28]. As mentioned above, public sector organizations, and local governments in particular, play a central role in delivering the sustainable development agenda $[3,29,30]$.

The literature on sustainability reporting in LGOs has reported on the SR in a single country, as introduced by Greco et al. [31], or in a multicultural context [17], discussing European LGOs in terms of sustainability disclosure and linking it with the administrative culture.

Only a few studies focused on understanding the characteristics and reasons for the preparation of SR in the public sector $[28,29,31-34]$ and even more limited are the studies that have attempted to understand the barriers to SR diffusion and adoption [16,35,36]. Ball and Grubnic [29] stated that the economic dimension and the environmental impact and responsibilities would be expected to influence sustainability reporting. According to Gray [32], institutions only disclose their SD activities if they are convinced that this increases the value perceived by the stakeholders. From this perspective, SR is perceived as promoting and enhancing accountability. The perceived lack of utility of SR by LGOs is therefore a limitation to their spread.

Marcuccio and Steccolini [34] completed thorough interviews of 12 Italian LGOs. They showed that LGOs' inclination to disclose and ability to provide information, in a non-mandatory SR framework, are the result of a drive to streamline organizations, without necessarily becoming more efficient. In a subsequent study, the same authors [8] found that the legitimacy process drove the reporting of sustainability matters. Another study with similar conclusions focused on 55 Spanish LGOs [37]. Contrary to competitive isomorphism, Powell and Di Maggio [38] proposed three forms of institutional isomorphism: (1) coercive isomorphism arises from requirements mandated by law; (2) mimetic isomorphism relates to the introduction of organizational excellence practices; and (3) normative isomorphism is the consequence of shared values about proper behavior, often widespread through professional communities. In this scenario, a barrier to the adoption of SR is the lack of legal requirement for SR.

First Mercer et al. [35], then Pini et al. [36], identified factors inhibiting the SR of LGOs in Australia. Graymore [16] outlined these factors, identifying that barriers are related to capacity (i.e., lack of financial resources), commitment (i.e., lack of support from key staff), coordination (i.e., lack of understanding of the various roles of LGOs), community (i.e., lack of interest from the community), and the complexity of sustainability. Graymore suggested a collaborative approach to encourage the application of SR in Australian LGOs. Few studies focused on a single country [39,40], so different cultures did not influence the results. The trend in SR over a long time period and the barriers that inhibit SR uptake were examined. This paper tries to fill the gaps in this area and contributes to the research field connecting trends and barriers over a long evaluation period.

To explain the sustainable behavior of local governments, the most common theoretical framework used in the literature is legitimacy theory $[8,32,37]$. Legitimacy theory suggests that the managers' choice to disclose sustainability information occurs because this communication contributes to legitimizing their actions and improves the government's or organization's reputation in the eyes of the citizens, despite financial problems [8]. In this framework, governments or managers could decide not to report sustainability information because it is not seen as a priority for their legitimation towards citizens. Thus they believe that the SR is not effective for building up their reputation (SR Low effectiveness, see Table 1); there is no commitment on sustainability matters in their agenda.

Furthermore, contingency theory defines organizations as composite systems of interdependent external and internal factors [41-43]. This theory emphasizes how contingencies such as size, environmental uncertainties, and environmental pressures affect organizations' behavior. With a focus on accounting research, the contingency theory is "based on the premise that there is no universally appropriate accounting system which applies equally to all organizations in all circumstances" [44]. In other words, this theory tries to identify the relationships between an organization's internal 
and external characteristics and its management capacity [45]. According to this framework, contingencies affect organizations' propensity to use reporting tools. Hence, the influence of different environmental features, structural characteristics, and organizational practices on sustainability report publication patterns is a relevant topic. Regarding external pressures, it should be emphasized that sustainability reporting is not imposed by Italian law (Voluntariness of SR, see Table 1) and on the other hand that there is a 2010 law that requires local governments to reduce by $80 \%$ the expenditure for publications, compared to 2009 expenditure. There is therefore a tangible external pressure that requires a strong reduction in expenditure in the communication and reporting sector (Cost reduction, see Table 1).

Table 1. Research framework.

\begin{tabular}{|c|c|c|}
\hline Theoretical Framework & $\begin{array}{c}\text { Barriers to Sustainability Reporting } \\
\text { (Based on Literature Review) } \\
{[8,16,35,36]}\end{array}$ & Barriers to SR in Our Survey \\
\hline Legitimacy theory & $\begin{array}{l}\text { No commitment on sustainability } \\
\text { matters-no priority to that }\end{array}$ & SR Low effectiveness \\
\hline \multirow{4}{*}{ Contingency theory } & Lack of financial and human resources & Cost reduction \\
\hline & No mandatory requirement & Voluntariness of SR \\
\hline & $\begin{array}{l}\text { Complexity of sustainability } \\
\text { topics-only one complex system in } \\
\text { place to report information (Global } \\
\text { Reporting Initiative guidelines for } \\
\text { non-commercial organizations) }\end{array}$ & Cost reduction \\
\hline & Small size & Size detected as an independent variable \\
\hline
\end{tabular}

Looking at the internal organization's characteristics, previous studies have shown how size is one of the features that most affects the choice to publish a sustainability report, which is widespread in large local governments [44]. In this regard, there are also studies relating to the private sector about the effect of company size on sustainability reporting. Findings showed that the size of the company has a positive influence on the reporting of corporate social responsibility initiatives [46,47]. To summarize, Table 1 explains the research framework applied in this paper.

\section{The Sustainability Reporting in Italian LGOs}

To explain the use of sustainability reporting by Italian LGOs, a brief description of the context follows. In Italy, about 8000 local governments exist, $70 \%$ of which are small LGOs for municipalities with fewer than 5000 inhabitants. Italian LGOs are responsible for the following areas: management of social services, land charges register management, urban and housing planning in the municipality, participation in territorial planning at a supra-municipal level, organization and management of garbage collection and related tax collection, school building, planning and management of school services, and municipal police. Since 1990, LGOs have had more autonomy when setting taxes and fixing fees for public services, and since 2010, they have experienced a heavy reduction in the number of transfers from the central government and have been driven to delegate their activities. Italian LGOs have undergone a wide-ranging reform process covering governance that defines the actions of politicians and managers and accounting systems. Moreover, the Italian PSOs are being pushed for greater accountability (accounting harmonization) and for cost reductions (austerity period). During this period, sustainability reporting has been one of the major issues of interest for experimentation in Italian LGOs [48].

In Italy, the theme of sustainability reporting was first studied in the 1980s [49] with a focus on the private sector. Since then, more research has been dedicated to the reporting tools used by Italian public sector organizations [6,34]. However, for SR in the Italian civil law system, public sector 
organizations voluntarily report their SR practices. Even if SR is not mandatory, public institutions can choose to disclose and report their decisions on sustainable issues based on the three national guidelines. These guidelines were created with the intent to increase the transparency of public sector organizations on social and environmental issues. The first guidelines were issued by Gruppo Bilancio Sociale (GBS Group) in 2005, whereas the other two were issued by public agencies: Presidenza del Consiglio dei Ministri, Dipartimento della Funzione Pubblica, and Osservatorio per la finanza e la contabilità degli enti locali-Ministero dell'Interno, in 2006 and 2007, respectively. In addition, Italian LGOs can refer to the international sustainability reporting guidelines issued by the Global Reporting Initiative.

For Italy, Siboni's work [10] is one of the few studies that empirically addressed the issue of social reporting. Through a survey involving 760 municipalities and all Italian provinces, Siboni empirically investigated the dissemination of accountability tools, including the social report. During sample selection, municipalities with a population less than 1999 inhabitants were excluded. The results, with particular reference to LGOs, highlighted a $13 \%$ use of SR by the respondents. Only a few LGOs claimed to involve stakeholders in their social reporting process, and even when this aspect is improved, it is only a simple mapping of the general stakeholders' classes, with no active involvement of identified stakeholders.

Considering the few LGOs that involved stakeholders in drafting the SR, Farneti et al. [50] analyzed the SR content. Through content analysis, they found that the SR prepared by these LGOs did not include all the voices outlined by the GRI framework in practice, and that social reports focused mainly on administrative and managerial matters.

Using another method, Farneti and Rammal [51] investigated the motives and influence of sustainability reporting in the Italian public sector. They conducted semi-structured interviews with key informants from nine Italian public sector organizations. They found that the source of the internal pressure for producing the SR is from individuals in positions that see SR preparation as a way to highlight the results they have achieved. External pressure for editorial work comes from stakeholders and the general population, and is the result of greater focus, including from the media, on environmental and social issues.

The study of Greco et al. [31] investigated the motivations of Italian local councils for producing a sustainability report. The study was based on semi-structured interviews with those that prepared the sustainability report of a sample of Italian local councils. The findings demonstrated that transparency seems to be the initial main driver of voluntary SR adoption, even if the stakeholders show limited interest in the findings of the sustainability report. Moreover, the authors highlighted that LGOs moved from traditional SR to more complete accountability policy-making and reporting tools, aimed at increasing citizen participation. From a regulatory point of view, there is no obligation in Italy to publish structured sustainability documents. However, obligations regarding transparency do exist, such as those introduced by the legislative decree on 14 March 2013, No. 33. This law confirms the link between financial information and transparency, where it clearly states:

Public administrations must publish the documents and annexes of the financial statement and of the final account within thirty days of their adoption, as well as the forecasted budgetary data. The summary should be synthetic, aggregated and simplified, and where necessary, include graphical representations in order to ensure complete comprehensibility.

As can be seen from the text, sustainability is not mentioned. In summary, in Italy no mandatory enforceable law for LGOs requires a sustainability disclosure; SR is seen as a "carrot" to meet citizen's expectations and increase stakeholder engagement, according to legitimacy and stakeholder theories. 


\section{Research Method}

A quantitative analysis technique was used to collect data. The email survey was conducted with a sample considered to be sufficiently large and representative to allow the generalization of the results obtained for the entire population. This technique resulted in obtaining a high number of data which places this study among those with the largest number of municipalities involved.

\subsection{Sample}

Stratified sampling was considered appropriate to use, in terms of cost and time, considering all 8003 Italian municipalities. LGOs were classified, according to the 31 December 2010 Italian National Institute of Statistics (ISTAT) criteria according to: size, measured based on the population, and geographical area. In relation to the size, 3 clusters were identified: 5000-20,000, 20,001-100,000, and $>100,001$. For geographical area, 4 clusters were identified: north-west, north-east, center, south, and islands. Once the population was stratified, a random extraction identified 1300 municipalities, accounting for $16.13 \%$ of the total, through random selection, proportionate to the various strata of the population of Italian municipalities.

The data obtained about the SR adoption were compared to the data recorded in a previous survey conducted with similar methodology with reference to the year 2009 [52]. As the main object of the survey was to ascertain the publication of the sustainability report, to create a more solid database, representatives from the 1300 municipalities were interviewed and we contacted the 314 local governments that had responded to the Giacomini survey for 2009.

\subsection{Questionnaire}

This study was one of the first using an email survey to collect data about sustainability reporting adoption [15]. With the aim of using an objective approach in the analysis, we decided to distribute a questionnaire to Chief Financial Officers (CFOs) that had to be completed by responding through certified email in March 2015 with a second recall in June 2015.

As the literature analysed suggests that, in the absence of an isomorphistic tendency resulting from coercive pressure, a reduction in SR spread would be expected. Therefore, the questions posed aimed at investigating barriers to drafting the SR. The questions were developed based on the objectives of the research, considering the indicators in the literature and the Italian context, summarized in the previous paragraphs. Based on this context, we focused on the municipalities' point of view. To include the majority of local authorities, a simple survey with only two questions was structured.

The questionnaire was arranged as follows:

(1) Did you prepare a SR for the 2013 fiscal year?

(2) If not, what was the motivation (barriers) that led to the non-publication of the SR?
a. Cost reduction
b. Voluntariness of SR report
c. SR low efficacy
d. Do not know

The hypothesized answers were related to the research framework described in Table 1 . Conceivably, several reasons for abandoning the SR exist: external pressures (reduction of funds), a non-binding context (SR is voluntary and not mandatory), or internal evaluations (SR judged ineffective).

The results were analyzed using both descriptive statistics and by investigating the possible relationships between the variables. The data obtained about the diffusion of the SR in 2013 were compared to the data recorded in a previous survey for 2009 that used the same methodology [52]. 
To ensure the reliability and truthfulness of the responses, the authors verified the online publication of the sustainability report on the websites of the local governments that responded to the questionnaire.

\subsection{Response Rate}

In surveys completed over the Internet, a rather limited response rate is common. An acceptable rate of response for this type of survey is 10\% [53]. In this study of 2013, a total of 234 usable responses were received, for a response rate of $18.0 \%$, whereas in 2009 , the response rate was $23.0 \%$ with 314 respondents [48]. Generally, the response rates of regular email surveys lacking a telephone follow-up or pre-contact typically vary between $6 \%$ and $16 \%$ [53]. We completed two rounds of follow-up for non-respondents.

\section{Results}

Only $4 \%$ of the municipalities, or 9 out of 234, prepared a SR in 2013. This result highlights a considerable decrease (Figure 1) from the 11\% that completed a SR in 2009. To ensure the reliability and truthfulness of the responses, the authors verified the online publication of the sustainability reporting in websites of those local governments that responded as having completed the SR.

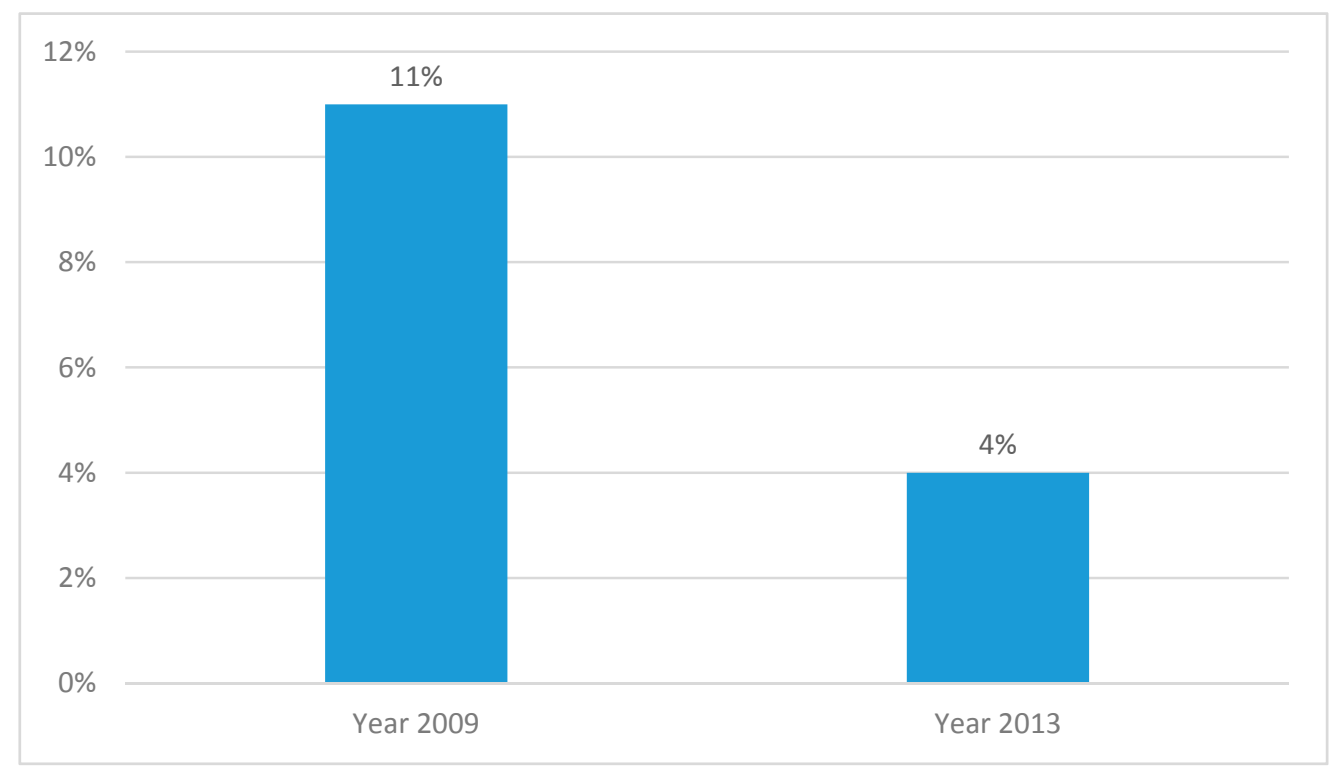

Figure 1. Completion of the sustainability report in 2009 and 2013.

The evident decline in the use of sustainability reports could be due to the managerial practices of the early 21st century that led to the introduction and distribution of the sustainability report [34]. After that, without a coercive approach or incentive for LGO to complete the SR, the process was abandoned by LGOs. The most recent trend demonstrates that the use of the SR has essentially disappeared. The answers can be further investigated considering the size of the LGOs. Data analysis (Table 2) showed a significant association between the population size and the sustainability report adoption (Pearson $\chi^{2}(2)=24.19 ; p<0.01$; Kendall's tau-b $=0.24$ ).

Only $1.2 \%$ of the municipalities belonging to the "fewer than 5000 " category completed the sustainability report. Similarly, $4.0 \%$ of the municipalities belonging to the "5000-20,000" category compiled the report. The results were different for the larger municipalities. For the municipalities belonging to the "20,000-100,000" and "more than 100,000" clusters, $16.7 \%$ and $50.0 \%$ compiled the report, respectively. In conclusion, the largest municipalities were most likely to prepare the sustainability report. 
Table 2. Adoption of the sustainability report in 2009 and 2013 in municipalities aggregated based on demographic and area criteria.

\begin{tabular}{|c|c|c|c|c|c|c|c|c|c|c|c|c|}
\hline \multirow{2}{*}{2013} & \multicolumn{3}{|c|}{ North } & \multicolumn{3}{|c|}{ Centre } & \multicolumn{3}{|c|}{ South } & \multicolumn{3}{|c|}{ Total } \\
\hline & No. & Total & $\%$ & No. & Total & $\%$ & No. & Total & $\%$ & No. & Total & $\%$ \\
\hline Fewer than 5000 & 1 & 94 & 1.1 & 0 & 21 & 0.0 & 1 & 47 & 2.1 & 2 & 162 & 1.2 \\
\hline $5001-20,000$ & 2 & 28 & 7.1 & 0 & 6 & 0.0 & 0 & 16 & 0.0 & 2 & 50 & 4.0 \\
\hline $20,001-100,000$ & 3 & 6 & 50.0 & 0 & 6 & 0.0 & 0 & 6 & 0.0 & 3 & 18 & 16.7 \\
\hline Over 100,000 & 2 & 4 & 50.0 & 0 & 0 & 0.0 & 0 & 0 & 0.0 & 2 & 4 & 50.0 \\
\hline Total & 8 & 132 & 6.1 & 0 & 33 & 0.0 & 1 & 69 & 1.4 & 9 & 234 & 3.8 \\
\hline \multirow{2}{*}{2013 Respondents for 2009} & \multicolumn{3}{|c|}{ North } & \multicolumn{3}{|c|}{ Centre } & \multicolumn{3}{|c|}{ South } & \multicolumn{3}{|c|}{ Total } \\
\hline & No. & Total & $\%$ & No. & Total & $\%$ & No. & Total & $\%$ & No. & Total & $\%$ \\
\hline Fewer than 5000 & 0 & 120 & 0.0 & 0 & 23 & 0.0 & 1 & 61 & 1.6 & 1 & 204 & 0.5 \\
\hline $5001-20,000$ & 2 & 37 & 5.4 & 0 & 9 & 0.0 & 0 & 22 & 0.0 & 2 & 68 & 2.9 \\
\hline $20,001-100,000$ & 2 & 12 & 16.7 & 1 & 4 & 25.0 & 1 & 9 & 11.1 & 4 & 25 & 16.0 \\
\hline Over 100,000 & 3 & 9 & 33.3 & 0 & 3 & 0.0 & 4 & 5 & 80.0 & 7 & 17 & 41.2 \\
\hline Total & 7 & 178 & 3.9 & 1 & 39 & 2.6 & 6 & 97 & 6.2 & 14 & 314 & 4.5 \\
\hline \multirow{2}{*}{2009} & \multicolumn{4}{|c|}{ North } & \multicolumn{3}{|c|}{ Centre } & \multicolumn{2}{|c|}{ South } & \multicolumn{3}{|c|}{ Total } \\
\hline & No. & Total & $\%$ & No. & Total & $\%$ & No. & Total & $\%$ & No. & Total & $\%$ \\
\hline Fewer than 5000 & 3 & 120 & 2.5 & 0 & 23 & 0.0 & 5 & 61 & 8.2 & 8 & 204 & 3.9 \\
\hline $5001-20,000$ & 9 & 37 & 24.3 & 2 & 9 & 22.2 & 2 & 22 & 9.1 & 13 & 68 & 19.1 \\
\hline $20,001-100,000$ & 5 & 12 & 41.7 & 0 & 4 & 0.0 & 0 & 9 & 0.0 & 5 & 25 & 20.0 \\
\hline Over 100,000 & 5 & 9 & 55.6 & 1 & 3 & 33.3 & 2 & 5 & 40.0 & 8 & 17 & 47.1 \\
\hline Total & 22 & 178 & 12.4 & 3 & 39 & 7.7 & 9 & 97 & 9.3 & 34 & 314 & 10.8 \\
\hline
\end{tabular}

By comparing the 2013 results with those obtained with reference to 2009, we observed the general decrease in the adoption of SRs except for LGOs with more than 100,000 inhabitants (Figure 2). These results were confirmed by examining the data for the year 2013 and the data from local governments that had responded to the 2009 survey. For 2009, the SR use was 3.9\% in LGOs in the less than 5000 category, $19.1 \%$ in the $5000-20,000$ cluster, and $20.0 \%$ in the $20,000-100,000$ cluster. The most important decrease was in the 5000-20,000: from 19.1\% in 2009 to $2.9 \%$ in 2013 recall.

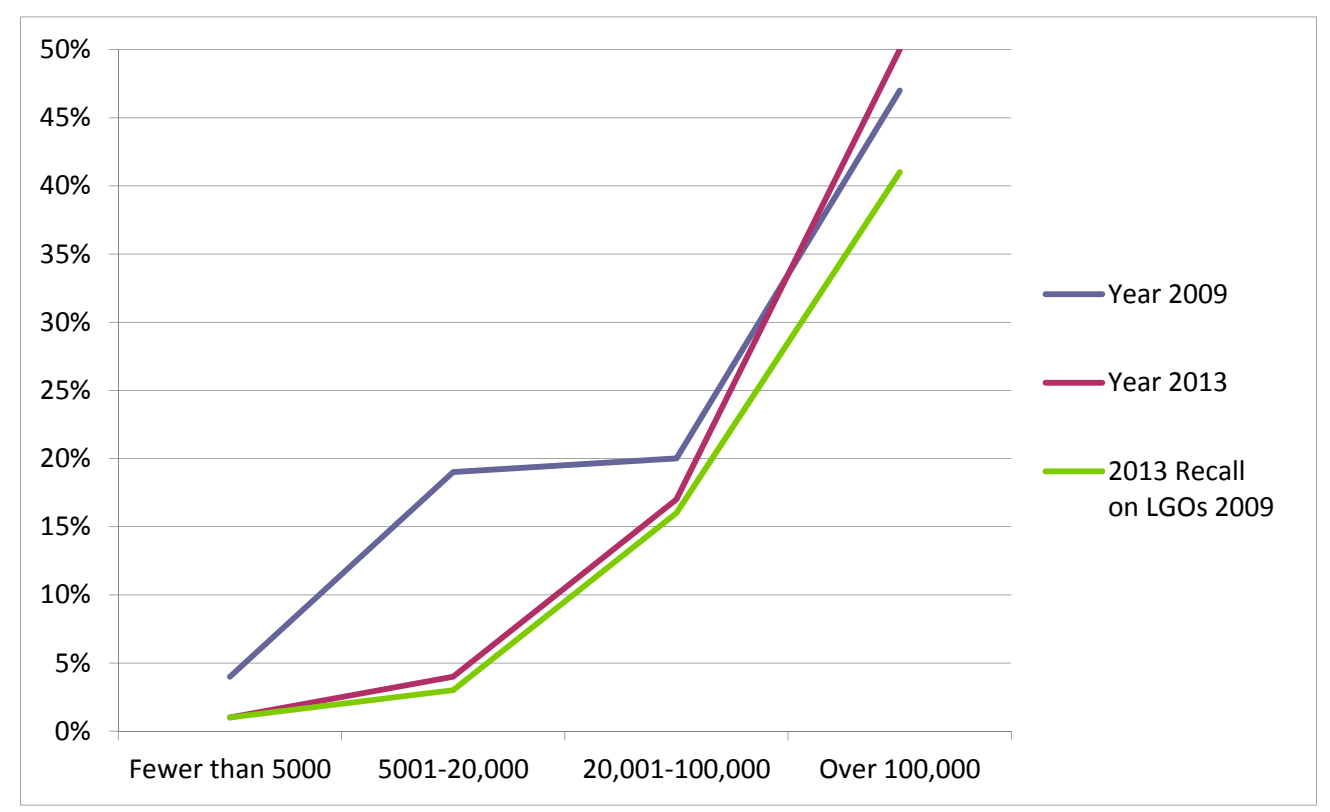

Figure 2. Adoption of the sustainability report in municipalities aggregated with demographic criteria for 2009 and 2013. 
For RQ 1, the results confirmed the suggestion in the literature about the lack of SR adoption without incentives or the mandated adoption of the reports, especially for smaller LGOs.

The results of the second research question, related to the barriers to SR adoption, are shown in Figure 3. The second question was close-ended; the options were constructed based upon the research framework determined by the authors (Table 1). The second question was only asked to the local governments included in the 2013 survey.

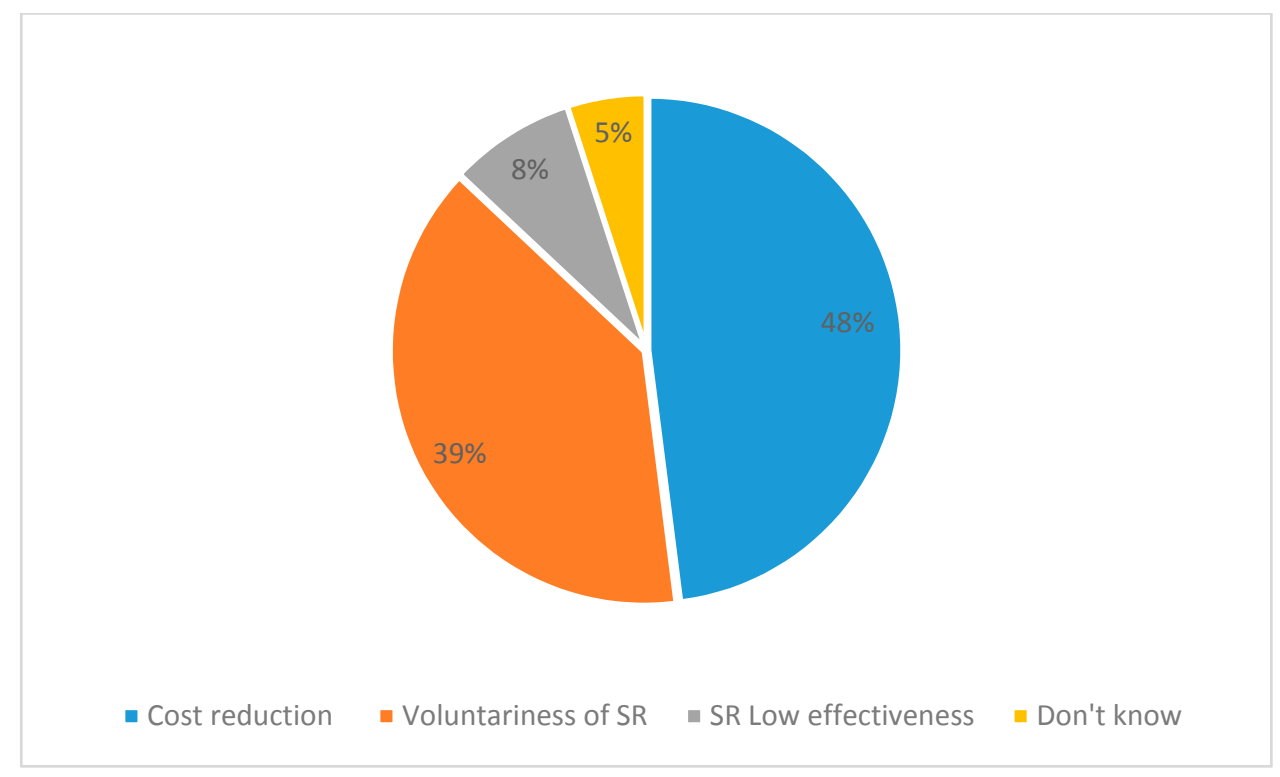

Figure 3. Reasons the sustainability report (SR) was not published in 2013.

The most common answer (Table 3) provided by the 225 municipalities was that cost reductions, related to austerity, represented a barrier to sustainability report preparation in terms of time and availability of staff $(48 \%)$. The voluntary nature of the reporting tool was the second reason, indicated by $39 \%$ of the municipalities surveyed. Only $8 \%$ of municipalities linked the SR to its usefulness.

Table 3. Reasons the SR was not published in 2013. Results are aggregated with demographic criteria.

\begin{tabular}{ccccc}
\hline & Cost Reduction & Voluntariness of SR & SR Low Effectiveness & Do Not Know \\
\hline Fewer than 5000 & $56 \%$ & $38 \%$ & $4 \%$ & $3 \%$ \\
$5001-20,000$ & $33 \%$ & $35 \%$ & $21 \%$ & $10 \%$ \\
$20,001-100,000$ & $20 \%$ & $60 \%$ & $13 \%$ & $7 \%$ \\
Over 100,000 & $0 \%$ & $100 \%$ & $0 \%$ & $0 \%$ \\
\hline
\end{tabular}

Examining the reasons that the SR was not published based on conditional demographic classes (Figure 4), the theme of the cost reduction most affected the smaller local governments. The result is not surprising: the preparation of the SR proportionally affects the budgets of small municipalities, although the effect on total expenditure in these cases is limited. In other words, the lack of financial resources devoted to SR influenced the significant reduction in the completion of a sustainability report in municipalities with fewer than 20,000 inhabitants. In medium-sized municipalities, with 20,000 to 100,000 inhabitants, and in the bigger cities with more than 100,000 inhabitants, the most relevant reason for non-completion was the voluntariness of the SR. So in these cases, the decline of SR phenomenon in LGOs appears to not be related to managerial practice but to the absence of a coercive isomorphism. In the municipalities with 5000 to 20,000 inhabitants, the barriers were equally distributed between cost reduction and the voluntariness of the report. 


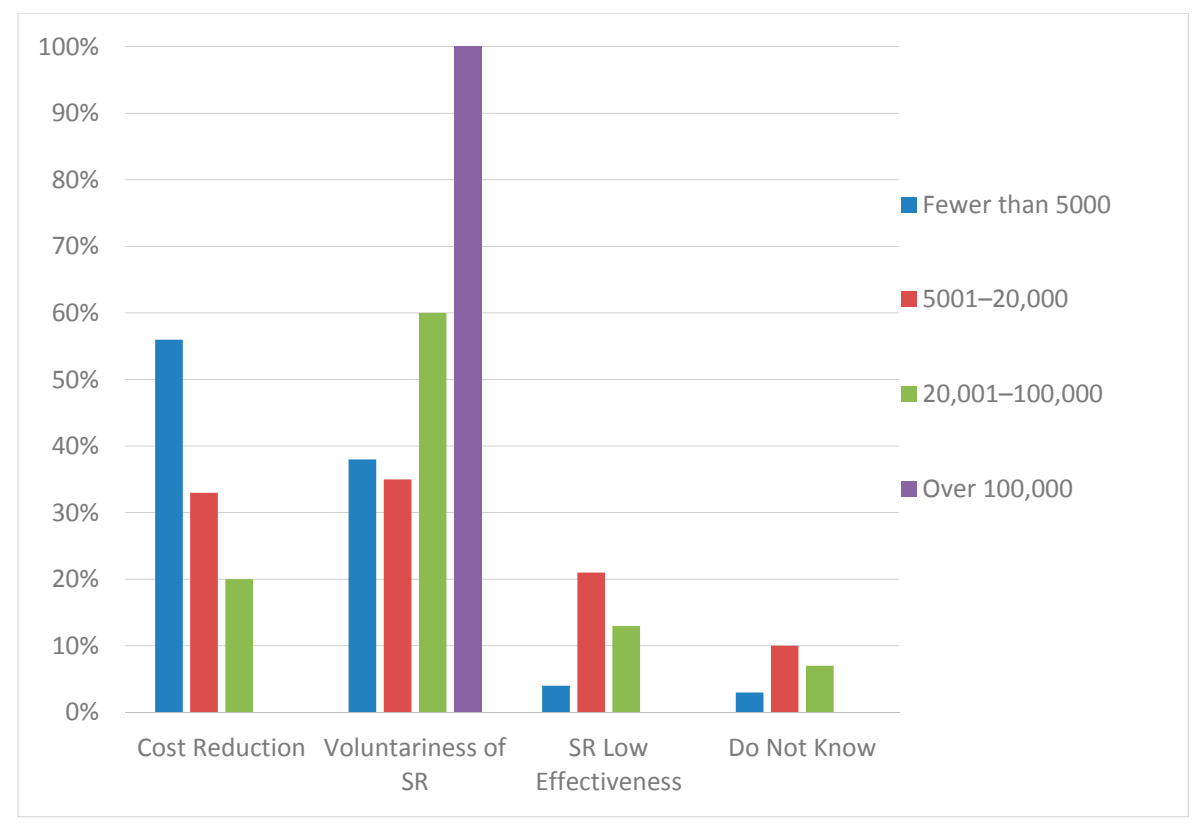

Figure 4. Reasons the SR was not published. Results aggregated with demographic criteria.

\section{Conclusions and Policy Implications}

Given the evidence emerging from empirical research, we formulated some conclusions and policy implications for the development of the uptake of sustainability reporting in Italian municipalities. As evident from the available data, the stick is better than the carrot in the Italian framework. Research demonstrated that the SR in LGOs was relevant but was showing a decreasing trend. Comparing data from 2009 to 2013 showed that a drastic reduction occurred in the completion of sustainability reporting. The main barriers to SR adoption are the prevalence of short-term goals, such as cost reduction, versus long-term goals, such as sustainability. As the voluntary nature of the SR has not led to a growth in sustainability reporting, the Italian LGOs focus solely on mandatory accounting obligations required by the central government (coercive isomorphism). The choice of the vast majority of municipalities to not draft a SR was not based on assessments of the usefulness of the reporting tool. The choice of the central government to promote sustainable development appears random. By creating a social accounting model addressed to local authorities through the Ministry of Public Organization, while simultaneously heavily cutting $(-80 \%)$ the resources allocated to LGOs for publications addressed to citizens, which also includes the SR. Italian LGOs received calls for accountability as well as for cost reductions, and they chose the latter. The barriers that are found in the survey validate the decreasing trend in SR use.

This article presents a quantitative analysis of sustainability reporting implementation in local government, responding to the need for studying sustainability accounting in local governments by providing a twofold contribution. First, this study provides quantitative data to support the trend in sustainability reporting among Italian LGOs. Faced with a growing academic interest in sustainability accounting and numerous theoretical contributions, a large-scale empirical survey on the longitudinal adoption of the phenomenon was considered necessary. Secondly, even for sustainability reporting, local politicians and public servants, rather than looking at the relationship with various stakeholders, priority is given to the regulatory requirements (coercive isomorphism). In the past, both the lack of recognized standards and the absence of incentive to change their environmental and social choices led local governments to ignore the importance of disseminating information about sustainability [54]. However, since the 2010s, LGOs have had the ability to choose among many frameworks and guidelines that have been implemented for sustainability reporting. Hence, this choice cannot explain the decision not to publish a sustainability report, as shown by 
$96 \%$ of the municipalities surveyed. Most of the sustainability reports were published by large municipalities, in line with previous findings [52]. We also confirmed the findings of other studies related to sustainability practices: according to contingency theory, the larger LGOs have more human and financial resources, hence they are more likely to engage in sustainable development [55].

In terms of policy implications, the results suggest that decision makers must consider that although socio-psychological forces can be sufficient to legitimize the introduction of a new technique in the short term, they cannot guarantee their long-term legitimacy, for which careful consideration of technological-economic forces is crucial [56]. In this regard, two policy implications can be implemented to overcome barriers to the use of the report. First, according to legitimacy theory, the SR could be promoted as a tool to legitimize the local politician's actions given its provision in political and electoral programs as the result of a sustainable development commitment. This could enhance accountability in the social and environmental aspects of LGOs. Energy efficiency (cost reduction), sustainable transport, and waste-to-energy policies are some of the initiatives that local politicians could introduce to achieve the sustainable development of their cities. Secondly, the introduction of an obligation is consistent with the context of local authorities that are highly responsive to the coercive pressure. The introduction of mandatory SR is risky: a reform enforced by law tends to become a matter of compliance rather than a mechanism for enabling change [57]. A related issue is that if LGOs are engaged in sustainability polices, new sustainable jobs could be created to fulfill these policy objectives. During a period of austerity, this new personnel cost could be balanced by cost reductions due to energy efficiency. New issues in public procurement would arise when promoting sustainable products and services, or when introducing new indexes for the evaluation of public contractor organizations to set new sustainable trends in the market [58].

Could the results of this study support a mandatory requirement for SR in LGOs as a "stick"? More research is needed in the public sector to confirm the feasibility of this option. At the moment, the "carrot" has been proven to be unsuccessful. These findings support the contingency theory, which states that external pressures and organizational factors cause innovation in public sector accountability systems. Furthermore, the role of information and accounting tools applied to sustainability deserves further attention. For example, Thomson et al. [59] discussed the concept of accounting sustainability hybrids [59].

As with any piece of research, this paper has limitations. First, the data for municipalities with more than 100,000 inhabitants should be improved. Although larger municipalities appear more likely to report (Tables 2 and 3), the sample size was probably too small to identify if population size is a significant factor. In addition, the quantitative analysis approach used in this article has limitations. Further work is required to better identify how sustainability reporting is practiced within the public sector, and how the choice to complete sustainability reporting is influenced by the values, interests, and pressures of internal and external stakeholders. Although the quantitative analytical approach used here produced generalizable results, case studies are needed to explore the role of political leadership and the values and skills of public managers in promoting SR practices.

Another limitation is that the stakeholder approach was not analysed within the survey in this paper because it should be studied not only from a LGO perspective but also from that of the stakeholders, such as citizens, NGOs, and local community delegates. This in-depth ad hoc analysis should be researched with a survey about the community perception of SR, with the addition of a qualitative case study.

Future research, both qualitative and quantitative, would help to better understand if and how providing information on sustainability issues would increase engagement in sustainability. In other words, the role of accounting in promoting sustainability practices in local governments should be determined.

The SR is only the final stage in the accountability process. A municipality may not complete a SR but this does not mean that the municipality has no social and environmental commitments in the local agenda, such as social commitment and assistance for the poor. Future research will study 
the other sustainability tools used by LGOs in Italy in the digital era, including social networks and website communication [60].

Moreover, European Directive 95/2014 requires all "large public interest entities" to start disclosing non-financial information. This could be a starting point for a similar directive or law for government at all levels. In Italy, the transposition of the Directive identifies public interest entities as those with more than 500 employees in the last year and that exceed at least one of the two following parameters: a total of 20 million euros on the balance sheet and 40 million euros in revenues. The introduction of a mandatory minimal sustainability report may also force municipalities to focus on sustainability due to the information flow process starting with the reporting obligation and reinforced by the subsequent coercive isomorphism. Information flow is the process by which the behavior of an individual is influenced by the information that must be disclosed [61].

Acknowledgments: This research did not receive any funding from any agency in the public, commercial, or not-for-profit sectors to support the work or to cover the costs to publish in open access.

Author Contributions: Davide Giacomini and Laura Rocca studied and wrote the literature review and theoretical framework; Davide Giacomini and Mario Mazzoleni designed the survey; Davide Giacomini collected data; Davide Giacomini and Cristian Carini analyzed the findings; Davide Giacomini, Mario Mazzoleni and Laura Rocca developed and wrote the conclusions and policy implications.

Conflicts of Interest: The authors declare no conflict of interest.

\section{References}

1. Brandon, P.; Lombardi, P. Evaluating Sustainable Development in the Built Environment, 2nd ed.; Wiley-Blackwell: Hoboken, NJ, USA, 2011.

2. United Nations, Rio +2020 . Report of the United Nations Conference on Sustainable Development, Rio de Janeiro, Brazil, 20-22 June 2012; p. 23. Available online: http://www.un.org/ga/search/view_doc.asp? symbol=A/CONF.216/16\&Lang=E (accessed on 8 January 2018).

3. Ball, A. Sustainability Accounting in UK Local Government: An Agenda for Research; ACCA Research Report; Certified Accountants Educational Trust: London, UK, 2002; p. 78.

4. Sciulli, N. The views of managers from a local coastal council on sustainability reporting issues: An Australian-based case study. Qual. Res. Account. Manag. 2011, 8, 139-160. [CrossRef]

5. Ball, A.; Bebbington, J. Editorial: Accounting and reporting for sustainable development in public service organizations. Public Money Manag. 2008, 28, 323-326. [CrossRef]

6. Guthrie, J.; Ball, A.; Farneti, F. Advancing sustainable management of public and not for profit organizations. Public Manag. Rev. 2010, 12, 449-459. [CrossRef]

7. Unerman, J.; Bebbington, J.; O’Dwyer, B. Sustainability Accounting and Accountability; Routledge: London, UK, 2007.

8. Marcuccio, S.; Steccolini, I. Patterns of Voluntary Extended Performance Reporting in Italian Local Authorities. Int. J. Public Sect. Manag. 2009, 22, 146-167. [CrossRef]

9. Bovens, M. From financial accounting to public accountability. In Bestandsaufnahme und Perspektiven des Haushalts—Und Finanzmanagements; Hill, H., Ed.; Nomos Verlag: Baden Baden, Germny, 2005.

10. Siboni, B. La rendicontazione sociale negli enti locali: Un fenomeno composito. Azienditalia 2007, 5, 337-344.

11. Giacomini, D. La diffusione del bilancio sociale nei comuni italiani. In Riflessioni D'impresa: Alla Ricerca di Nuovi Paradigmi; Mazzoleni, M., Ed.; Giappichelli: Torino, Italy, 2013.

12. Pezzey, J. Sustainability: An Interdisciplinary Guide. Environ. Values 1992, 1, 321-362. [CrossRef]

13. Homann, K. Sustainability: Politikvorgabe oder regulative Idee? In Ordnungspolitische Grundfragen Einer Politik der Nachhaltigkeit; Gerken, L., Ed.; Nomos: Baden Baden, Germany, 1996; pp. 33-47.

14. Murcott, S. What is Sustainability? In Proceedings of the Sustainability Indicators Symposium, AAAS Annual Conference, IIASA, Seattle, WA, USA, 16 February 1997.

15. Williams, B.; Wilmshurst, T.; Clift, R. Sustainability reporting by local government in Australia: Current and future prospects. Account. Forum 2011, 35, 176-186. [CrossRef]

16. Graymore, M. Sustainability Reporting: An Approach to Get the Right Mix of Theory and Practicality for Local Actors. Sustainability 2014, 6, 3145-3170. [CrossRef] 
17. Navarro-Galera, A.; Ruiz-Lozano, M.; Tirado-Valencia, P.; de los Ríos-Berjillos, A. Promoting Sustainability Transparency in European Local Governments: An Empirical Analysis Based on Administrative Cultures. Sustainability 2017, 9, 432. [CrossRef]

18. Guthrie, J.; Abeysekera, I. Content analysis of social, environmental reporting: What is new? J. Hum. Resour. Costing Account. 2006, 10, 114-126. [CrossRef]

19. Parker, L. Social and environmental accountability research: A view from the commentary box. Account. Audit. Account. J. 2005, 18, 842-860. [CrossRef]

20. Habek, P.; Wolniak, R.; Quant, Q. Assessing the quality of corporate social responsibility reports: The case of reporting practices in selected European Union member states. Qual. Quant. 2016, 50, 399-420. [CrossRef] [PubMed]

21. Szczepankiewicz, E.I.; Mucko, P. CSR Reporting Practices of Polish Energy and Mining Companies. Sustainability 2016, 8, 126. [CrossRef]

22. Valor, C.; Zasuwa, G. Quality reporting of corporate philanthropy. Corp. Commun. Int. J. 2017, 22, 486-506. [CrossRef]

23. Sethi, S.P.; Martell, T.F.; Demir, M. An evaluation of the quality of corporate social responsibility reports by some of the world's largest financial institutions. J. Bus. Ethics 2017, 140, 787-805. [CrossRef]

24. Böhling, K.; Murguía, D.I.; Godfrid, J. Sustainability Reporting in the Mining Sector: Exploring Its Symbolic Nature. Bus. Soc. 2017. [CrossRef]

25. Ball, A. A sustainability accounting project for the UK local government sector? Mapping theories of social, environmental and sustainability accounting and locating a frame of reference. Crit. Perspect. Account. 2004, 15, 1009-1035. [CrossRef]

26. Ball, A. Environmental accounting and change in UK local government. Account. Audit. Account. J. 2005, 18, 346-373. [CrossRef]

27. Dumay, J.; Guthrie, J.; Farneti, F. GRI sustainability reporting guidelines for public and third sector organizations. Public Manag. Rev. 2010, 12, 531-548. [CrossRef]

28. Niemann, L.; Hoppe, T. Sustainability reporting by local governments: A magic tool? Lessons on use and usefulness from European pioneers. Public Manag. Rev. 2017, 19, 201-223. [CrossRef]

29. Ball, A.; Grubnic, S. Sustainability accounting and accountability in the public sector. In Sustainability Accounting and Accountability; Unerman, J., Bebbington, J., O’Dwyer, B., Eds.; Routledge: London, UK, 2007; pp. 243-465.

30. Larrinaga-Gonzalez, C.; Bebbington, J. Accounting change or institutional appropriation?-A case study of the implementation of environmental accounting. Crit. Perspect. Account. 2001, 12, 269-292. [CrossRef]

31. Greco, G.; Sciulli, N.; D'Onza, G. The Influence of Stakeholder Engagement on Sustainability Reporting: Evidence from Italian local councils. Public Manag. Rev. 2015, 17, 465-488. [CrossRef]

32. Gray, R. Social, environmental and sustainability reporting and organizational value creation? Whose value? Whose creation? Account. Audit. Account. J. 2006, 19, 793-819. [CrossRef]

33. Frost, G.; Seamer, M. Adoption of Environmental Reporting and Management Practices: An Analysis of New South Wales Public Sector Entities. Financ. Account. Manag. 2002, 18, 103-127. [CrossRef]

34. Marcuccio, M.; Steccolini, I. Social and Environmental reporting in local governments: A new Italian fashion? Public Manag. Rev. 2005, 7, 155-176. [CrossRef]

35. Mercer, D.; Jotkowitz, B. Local Agenda 21 and Barriers to Sustainability at the Local Government Level in Victoria, Australia. Aust. Geogr. 2000, 31, 163-181. [CrossRef]

36. Pini, B.; Wild River, S.; Haslam McKenzie, F.M. Factors Inhibiting Local Government Engagement in Environmental Sustainability: Case studies from rural Australia. Aust. Geogr. 2007, 38, 161-175. [CrossRef]

37. Alcaraz-Quiles, F.J.; Navarro-Galera, A.; Ortiz-Rodríguez, D. Factors determining online sustainability reporting by local governments. Int. Rev. Adm. Sci. 2015, 81, 79-109. [CrossRef]

38. Powell, W.; Di Maggio, P. The Iron Cage Revisited: Institutional Isomorphism and Collective Rationality in Organizational Fields. In The New Institutionalism in Organizational Analysis; Powell, W., Di Maggio, P., Eds.; University of Chicago Press: Chicago, IL, USA, 1991.

39. Navarro-Galera, A.; Tirado-Valencia, P.; Ruiz-Lozano, M.; de los Rios Berjillos, A. Divulgation of information on social responsibility of European local governments. The case of the Nordic countries. Manag. Public Policy 2015, 1, 229-270. 
40. Navarro-Galera, A.; Ruiz-Lozano, M.; de los Ríos Berjillos, A.; Tirado-Valencia, P. Corporate social responsibility in local governments: The case of the United Kingdom and Ireland. Innovate 2014, 24, 89-105.

41. Lawrence, P.R.; Lorsch, J.W. Differentiation and integration in complex organizations. Adm. Sci. Q. 1967, 12, 1-47. [CrossRef]

42. Chenhall, R. Management control systems design within its organizationalcontext: Findings from contingency-based research and directions for the future. Account. Organ. Soc. 2003, 28, 127-168. [CrossRef]

43. Thomas, A. Towards a contingency theory of corporate financial reportingsystem. Account. Audit. Account. J. 1991, 4, 40-57. [CrossRef]

44. Otley, D. The contingency theory of management: Achievement and prognosis. Account. Organ. Soc. 1980, 5 , 413-428. [CrossRef]

45. Ryan, C.; Stanley, T.; Nelson, M. Accountability Disclosures by Queensland Local Government Councils: 1997-1999. Financ. Account. Manag. 2002, 18, 261-289. [CrossRef]

46. Hou, J.; Reber, H.B. Dimensions of disclosures: Corporate social responsibility (CSR) reporting by media companies. Public Relat. Rev. 2011, 37, 166-168. [CrossRef]

47. Khan, H. The effect of corporate governance elements on corporate social responsibility (CSR) reporting. Int. J. Law Manag. 2010, 52, 82-109. [CrossRef]

48. Giacomini, D. Accountability in Italian Local Governments: State of the Art and Future Perspective. In Local Governments in the Digital Era: Looking for Accountability, 1st ed.; Cuadrado-Ballesteros, B., García-Sánchez, I., Eds.; Nova Publishers: Hauppauge, NY, USA, 2016.

49. Matacena, A. Impresa e Ambiente; CLUEB: Bologna, Italy, 1984.

50. Farneti, F.; Guthrie, J.; Siboni, B. Social reports in Italian local governments: What is not reported. In Social Accounting and Public Management. Accountability for the Common Good; Osborne, S.P., Ball, A., Eds.; Routledge: London, UK, 2011; pp. 192-202.

51. Farneti, F.; Rammal, H. Sustainability Reporting in the Italian Public Sector: Motives and Influences. In Proceedings of the Apira Conference, Kobe, Japan, 26-28 July 2013.

52. Giacomini, D. Rendicontazione Sociale e Public Accountability nei Comuni Italiani. Ph.D. Thesis, University of Parma, Parma, Italy, 2012.

53. Harzing, A.W. Response rates in international mail surveys: Results of a 22-country study. Int. Bus. Rev. 1997, 6, 641-665. [CrossRef]

54. Yongvanich, K.; Guthrie, J. An extended performance reporting framework for social and environmental accounting. Bus. Strat. Environ. 2006, 15, 309-321. [CrossRef]

55. Laurian, L.; Walker, M.; Crawford, J. Implementing Environmental Sustainability in Local Government: The Impacts of Framing, Agency Culture, and Structure in US Cities and Counties. Int. J. Public Adm. 2016, 40, 270-283. [CrossRef]

56. Benders, J.; Van Veen, K. What's in a fashion? Interpretive viability and management fashions. Organization 2001, 8, 33-53. [CrossRef]

57. Panozzo, F. Management by decree. Paradoxes in the reform of the Italian public sector. Scand. J. Manag. 2000, 16, 357-373. [CrossRef]

58. Witjes, S.; Lozano, R. Towards a more Circular Economy: Proposing a framework linking sustainable public procurement and sustainable business models. Resour. Conserv. Recycl. 2016, 112, 37-44. [CrossRef]

59. Thomson, I.; Grubnic, S.; Georgakopoulos, G. Exploring accounting-sustainability hybridization in the UK public sector. Account. Organ. Soc. 2014, 39, 453-476. [CrossRef]

60. Navarro Galera, A.; de los Ríos Berjillos, A.; Lozano, R.M.; Valencia, T.P. Transparency of sustainability information in local governments: English-speaking and Nordic cross-country analysis. J. Clean. Prod. 2014, 64, 495-504. [CrossRef]

61. Prakash, P.; Rappaport, A. Information inductance and its significance for accounting. Account. Organ. Soc. 1977, 2, 29-38. [CrossRef]

(C) 2018 by the authors. Licensee MDPI, Basel, Switzerland. This article is an open access article distributed under the terms and conditions of the Creative Commons Attribution (CC BY) license (http:// creativecommons.org/licenses/by/4.0/). 